ELORE (ISSN 1456-3010), vol. 15 - 1/2008.

Julkaisija: Suomen Kansantietouden Tutkijain Seura ry.

[http://www.elore.fi/arkisto/1_08/kli1_08.pdf]

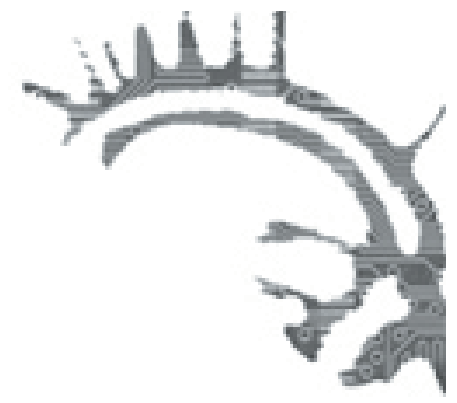

\title{
KOLUMNEN:
}

\section{I ÅLDERSKATEGORIERNAS GREPP}

\section{$\underline{\text { Sven-Erik Klinkmann }}$}

Jag fick en uppmaning av redaktörerna för det här temanumret om ålderskategoriforskning att skriva en kolumn om varför det förekommer så lite så kallad vuxenforskning, trots att väl så gott som samtliga ålderskategoriforskare kan klassificeras som vuxna. Finns här alltså ett slags paradox gömd som utgörs av att den kategori som forskarna själva tillhör, inom det fält som etablerats, ålderskategorier, helt enkelt blivit över, att den befinner sig för nära betraktaren för att uppfattas som tillräckligt intressant som föremål för en kulturanalys och en forskningsinsats av något slag?

Man kan närma sig de här frågorna från en rad olika håll, förvisso. Här ämnar jag försöka ställa några frågor som jag inte alls är så säker på att jag ens har några svar på, frågor som dels har att göra med själva fältet och dess förutsättningar, dels med forskningen om detta fält. Eller mer konkret tänkte jag fråga mig vilka underliggande faktorer av social och psykologisk art som ligger bakom vårt tänkande kring begreppet ålderskategori i dag, och även se efter om man kan säga något om eller åtminstone spekulera kring faktorer som påverkat utvecklingen av detta "svarta hål", om det nu är ett svart hål, i kulturforskningen, alltså bristen på forskning om vuxenhet. Eftersom jag är folklorist med populärkultur som mitt egentliga forskningsområde (eller mer exakt stereotyper, ikoner, anakronismer, populära fantasier i populärkulturen) kommer jag att närma mig frågorna från den speciella utkikspunkt jag har forskningsmässigt, vilket också betyder att jag ger en del exempel på frågeställningar vad gäller ålderskategoritänkande som dykt upp i min egen forskningspraktik.

En utgångspunkt för en reflexion kring ålderskategoribegreppen kan vara den starkt polemiska syn på ålderskategorier i det västerländska (läs svenska) samhället som på ett slagkraftigt sätt formulerats av etnologen Karl-Olov Arnstberg (i tidskriften Axess 2/2002). Arnstberg hävdar att samhället i dag har fått vad han kallar en beröringsskräck för det gamla. Till skillnad från traditionella samhällen där generellt vuxenhet och speciellt hög ålder implicerat klokhet och vishet kännetecknas vår egen tid enligt Arnstberg av slagordet "ungdomens makt förtrollar och förgör". Han konstaterar vidare att denna dyrkan av ungdom baserar sig på ett slags kroppens värde. Det är inte tänkandet i sig man är speciellt intresserad av, däremot av att man 


\section{I ÅLDERSKATEGORIERNAS GREPP}

kan ha en kropp som inte är behäftad med olika krämpor, en kropp som lyder och dessutom är behaglig att beskåda:

Den unga kroppens värde är starkt markerat i såväl moderna som traditionella kulturer. Den som är ung i vårt samhälle anses dock vara överlägsen genom att vara bättre synkroniserad med sin egen tid. Ju äldre man är i ett modernt samhälle, desto mer ur tiden är man. Den som är gammal klarar inte datorer, inte den moderna trafiken, inte all avancerad elektronik. Mormödrar och farfäder klarar nästan inte att sätta på radion själva, ännu mindre att ställa in tv:n. De gamla hänger inte längre med, som det kan heta. Därvid handlar det inte främst om att takten är för hög, utan om att utvecklingen, det framsteg som modernismen hyllar mer än någonting annat, förutsätter att unga människor ständigt tar vid för att föra modernismens stafettpinne vidare. (Arnstberg 2002.)

Vilka faktorer är det alltså - förutom den teknologiska utvecklingen - som lett till denna dyrkan av ungdomen, denna ensidiga inriktning på den unga kroppen som en norm i dagens samhälle? En viktig potentiell förklarande faktor brukar dyka upp lika snabbt som själva ämnet introduceras, nämligen kopplingen mellan vår ungdomsfixering och vårt allt starkare beroendeförhållande till en massmedialiserad verklighet. De mediala ikonerna, typ Elvis, Jim Morrison, Cher, James Dean, Madonna, Britney Spears, Spice Girls och många andra, är utpräglat ungdomliga ikoner, ikoner som antingen dött unga eller som på konstgjord väg lyckats bibehålla sin ungdomlighet in i vuxenlivet. Mycket riktigt är det just till populärkulturen Arnstberg först söker sig när han vill få oss övertygade om att hans starkt tudelade bild av ålderskategoriseringen äger ett bevisvärde. Han nämner den amerikanska sångerskan och skådespelerskan Cher som ju sägs ha lagt ner en förmögenhet på föryngrande skönhetsoperationer. Men tiden vinner också över Cher, konstaterar Arnstberg. Enda sättet att behålla sin ungdomliga image på är att dö, tillägger han: 'Det krävs en viss ansträngning att föreställa sig James Dean och Marilyn Monroe som gamla." Som ett bestickande argument för vart ungdomsfixeringen leder nämner han gamla hollywoodstjärnor, som gjort någon skönhetsoperation för mycket. I Hollywood lär det vara svårt att hitta vackert åldrade skådespelare, konstaterar han och fortsätter: "Nästan alla har i kampen för att behålla sin ungdom investerat så mycket i plastikkirurgi att de inte längre kan ställas framför en kamera. De ser inte bara gamla utan också väldigt konstiga ut. Ungdomen är i det här perspektivet inte ett skede i livet utan ett socialt kapital.”

\section{UNGDOM OCH UNGDOMLIGHET}

Jag har själv skrivit om den glidning i begreppsapparaten kring ungdom som man kan iaktta vad gäller en rock/popikon som Elvis. Det är egentligen, så snart man ska undersöka en representation av detta slag, nästan omöjligt att komma ifrån 


\section{Sven-ERIK KLINKMANN}

den metaforisering av begreppet som sätter in. Det uppstår en svävning mellan ett ålderskategoribegrepp, ungdom, och ett metaforiserat ungdomsbegrepp, ungdomlighet. Till skillnad från ålderskategoribegreppet kan ungdomlighet konnotera just sin gränsöverskridande ungdomlighet, det vill säga vissa egenskaper som sedan kan analyseras närmare, också hos personer som uppnått så kallad mogen ålder. Bakom begreppen hittar man åtminstone tre olika ungdomsdiskurser: adolescens, ungdom och ungdomlighet. Speciellt det sistnämnda ungdomsbegreppet, ungdomlighet, kommer att stå för en känsla av ungdom/ungdomlighet eller ett sökande efter ungdom och ungdomlighet, någonting som inte alls behöver vara kopplat till någon speciell ålderskategori. Begreppet ungdomlighet blir också inom en sådan förståelseram snabbt ett möjligt exploateringsområde för olika slags produkter som marknadsför och säljer "ungdom på burk", "evig ungdom", elixir eller tekniker som ska förhindra ett åldrande hos kroppen (Klinkmann 2002, se även Klinkmann 2007). I mina texter om ungdomlighetsdiskurser har jag hänvisat till kulturforskaren Efrat Tseëlons beskrivningar av "evigt unga" kvinnor, kvinnor som ännu vid 70 års ålder har ett ansikte utan rynkor eller vid 50 års ålder fortfarande är slanka, solbrända och perfekta (Tseëlon 1998).

En paradox i det metaforiserade ungdomsbegreppet är att ungdomligheten här som begrepp kommer att framstå som mest åtråvärd i det skede av livet när dess "mimetiska" sida eller presentation (ungdomsåren) redan ligger långt bakom en. Fantasin om en livets och ungdomlighetens källa blir inom ramen för ett sådant tankemönster ett slags logisk kulminationspunkt eller en "omöjlig" utopi som likt en hägring dyker upp någonstans vid den kroppsliga ökenvandringens horisont. Begreppet ungdomlighet blir därmed användbart i ett kommersiellt syfte. Men ett annat sätt att arbeta med begreppet ungdomlighet kunde vara att använda det som ett analytiskt redskap för en förståelse av mänskliga behov och olika uttryck för åtrå, längtan. Därmed kunde ordet bli användbart $\mathrm{i}$ analyser inom ämnesområden som till exempel symbolantropologi, folkloristik eller etnologi.

Man kan speciellt notera att just ungdom och ungdomlighet vad gäller analysen av rotmetaforer, symboler och symbolfält etablerats med hjälp av mycket envetna, starka sådana. Inte minst liminalitet (Martin 1981), coolness (Klinkmann 2002) och transgressivitet (Reynolds \& Press 1995) har ofta i kulturanalys kopplats till just ungdoms- och ungdomlighetsbegrepp och -diskurser. En fin sammanfattning av sammankopplingen hittar man i rockforskaren Ulf Lindbergs beskrivning av det han kallar symbolkretsar inom rockmusiken, som ju setts som en ungdomsmusik par préférence i det moderna och postmoderna samhället. Lindberg (1995) urskiljer följande fem centrala symbolkretsar inom rockmusiken: symboler för det ursprungliga, vilda, primitiva; symboler för det låga, vulgära, orena; symboler för det gränsöverskridande, tvetydiga, sammansatta; symboler för det upphöjda, melodramatiska och symboler för det framtida, utopiska. Att en ålderskategori med en så stark symbolisk uppbackning kommer att te sig kraftfull och attraktiv är självfallet inget större under, snarare en högst logisk slutsats utgående ifrån de givna förutsättningarna.

Vilka symbolkretsar har vuxenhet att ställa upp mot detta? Gråhet (för en diskussion om en rad nyanser av grått hos en vuxen anti-hjälte, yrkesmördaren Vin- 


\section{I ÅLDERSKATEGORIERNAS GREPP}

cent, spelad av Tom Cruise, i Michael Manns thriller Collateral, se Klinkmann 2005), tråkighet, mainstream, ansvar, plikt, auktoritet, småborgerlighet? Av en händelse blickar jag ner på golvet i mitt arbetsrum och mycket riktigt öppnar sig än en gång en bild av ungdomlighet och uppkäftighet. Pärmbilden till en ny bok om rockkultur, skriven av forskaren Björn Horgby, Rock och uppror (2007), utgörs av den "emblematiska" bilden av en ung, höftvickande Elvis Presley på scenen. Horgby behandlar uttryckligen rock som liktydigt med uppror. Jag tittar snabbt i innehållsförteckningen och hittar kapitelrubriker som "den moraliska ordningen, sexualitet som hot och upproriskhet", "den sociala ordningen, maskulinitet, hegemoni och upproriskhet", "den politiska ordningen, kampen om den politiska diskursen" och "kampen om hegemonin". Stora frågor har tydligen stått på spel inom denna ungdomsrelaterade kulturform som rocken traditionellt setts som.

Samtidigt har man dock alltmer, i vad som kanske kan kallas en sociologisk vändning i rockforskningen, börjat närma sig området rock inte i första hand som tidigare som en fråga om ungdom och ungdomlighetskultur, stil och subkultur (med inom rockforskningen moderna standardverk som Dick Hebdiges Subculture: the Meaning of Style och svensken Erling Bjurströms Högt \& laggt: Smak och stil $i$ ungdomskulturen). När rockkulturen åldrats och blivit "vuxen,", när många av de stora rockikonerna och -fansen kommit in i medelåldern och övre medelålern, för att inte tala om pensionsåldern, har man börjat upptäcka att rock kanske framför allt är en generationsmusikform, mindre en ungdomsmusikform. Joseph A. Kotarba har pekat på rockmusikens allt viktigare roll som timepiece, alltså klocka, tidtagare. Kotarbas argument för sin typ av rockforskning lyder:

I will argue that the concept of the cohort is more useful than that of the decade for an interpretive analysis of musical nostalgia, a key feature of the phenomenon in question. Illustrations of the reflexive relationship between rock ' $n$ ' roll and time in middle age include using awareness of recent deaths of rock 'n' roll performers to interpret the existential significance of aging; using rock 'n' roll songs as benchmarks for significant events such as birthdays and anniversaries, as well as gift giving for these events; and using rock 'n' roll music to pass the time. (Kotarba 2002.)

Därmed kommer rockmusiken på ett märkligt och samtidigt relevant sätt att i dag framstå som alldeles särskilt en musik för vuxna, mindre en musik för ungdomar. När jag för någon vecka sedan befann mig på en skivmässa här i min hemstad tillsammans med en mängd andra som var intresserade av framför allt rockmusik, men även jazz, annan populärmusik, och framför allt av formatet vinyl som ju tidsmässigt sammanfaller med det man kan kalla rockmusikens centrala tidsperiod (1950- till 1980-tal), då visade det sig att en majoritet av både kunder och försäljare på skivmässan bestod av personer som både ålders- och könsmässigt påminde om mig själv, manliga så kallade baby boomers, födda på 1940- och 1950-talen. Personer i vuxen ålder, alltså. 


\section{SVEN-ERIK KLINKMANN}

\section{VUXENHET SOM "COMING OF AGE"}

En annan ingång till frågan om vuxenhet som ålderskategori inom populärkulturen och därmed också som ett viktigt potentiellt fält för kulturforskning är det som på engelska kallas "coming of age", det vill säga egentligen liktydigt med ett slags etnologiskt och folkloristiskt grundbegrepp i van Genneps, Turners med flera kulturforskares anda, alltså övergångsritualer av olika slag. De analytiska kraven vad gäller att definiera denna typ av övergångsritualer kan jag av förklarliga skäl (detta är en tämligen fritt utformad, essä-artad text, ingen vetenskaplig artikel av ett mer traditionellt slag) här inte ställa speciellt högt. Det räcker med att försöka se efter i vilka sammanhang vad gäller populära filmer, musik och andra populärkulturella former frågan om att bli vuxen är central, det vill säga detta att övergå från en status som ungdom till en status som vuxen, och vilka faktorer som förefaller viktiga härvidlag.

Jag väljer exemplen för diskussionen från filmens värld, inte minst för att det där är speciellt lätt att hitta övergångsfaser av det här slaget. Jag behöver inte gå längre än till Disney för att finna ett exempel på en sådan kontext där hjälten rör sig från omognad till mognad, från ungdom till vuxenliv. Filmen jag tänker på är Lejonkungen. Jag läser ur en studentuppsats $i$ en kurs om symbolteori jag nyligen gav om just den filmens betydelse ur ett ålderskategoriperspektiv. Skribenten Jessica Björkqvist konstaterar att man hos filmens hjälte, lejonet Simba, kan se tre livsfaser som vi alla går igenom. Faserna är barndomen, tonåren och vuxendomen:

I sin barndom är Simba den dumristiga lejonungen som vill visa sitt mod och inte kan vänta på att få bli kung och visa sin styrka. I likhet med de flesta barn ser han inte riktigt alla faror utan upplever allt som lek. I tonåren har Simba mött Timon och Pumbaa som övertalar honom att följa mottot 'Hakuna matata', inga bekymmer. Han lägger sina problem bakom sig och förtränger bland annat sin pappas död som han känner sig skyldig till. Men problemen tynger honom ändå och han vet inte riktigt vem han är. Såväl identitetskris som kärlek stöter denna typiska tonåring på, fastän han i filmen är gestaltad som ett lejon. Till sist måste Simba ta itu med sina problem och möta sitt förflutna. Han är tvungen att strida mot sin farbror och ta över makten som kung. Han klarar detta och räddar lejonriket och därmed hela djurriket från dess undergång. Vid detta skede är han vuxen. (Björkqvist 2008; citerad med skribentens samtycke.)

Den här typen av hjälteberättelser utgör idag en helt central kategori av filmberättelser som attraherar en stor publik och därmed tycks ha en grundmurad position vad gäller populärkulturens sätt att via bilder och drömmar aktualisera existentiella frågor om liv och död, ansvar och skuld, sorg, kamp och vedermödor, där hjältefigurer av olika slag kommer att personifiera olika idealbilder av egenskaper, som mod, lojalitet, trofasthet, vänskap, påhittighet, list etc. Spektret av filmer där hjälten från en position som ung, oerfaren, närmast barnslig person blir en hjälte som axlar ansvar av betydande mått är mycket stort. Jag nämner här några sådana filmer där hjälte- 


\section{I ÅLDERSKATEGORIERNAS GREPP}

eller hjältinnemotivet är centralt sammankopplat med den här statusförändringen: Mel Gibsons Apocalypto, om indianen Jaguartass' heroiska kamp för att överleva i en förtryckande kultur (Maya-kulturen), Jason Bourne-trilogin The Bourne Identity, The Bourne Supremacy och The Bourne Ultimatum om den hemlige agenten Jason Bourne som lider av identitets- och minnesförlust och gradvis lär sig vem han egentligen är, genom att bli varse vilka hans fiender är, samt hjältarna Luke Skywalker, Han Solo och hjältinnan, prinsessan Leia i Star Wars-cykeln. Exemplen kunde mångfaldigas. Filmhistorien kan rada upp ett pärlband av sådana hjältar som räddar sig själva och den värld de är satta att fungera i.

Som religionsvetaren Sofia Sjö visat i sin doktorsavhandling Spelar kön någon roll när man räddar världen? Kvinnor, kvinnligheter och messiasmyter i SF-film (2007) är numera hjälteroller med messianska proportioner inget som är förbehållet enbart män. Filmer som Alien- och Terminator-cyklerna, eller Guillermo del Toros Pans Labyrint och tv-serien Buffy The Vampire Slayer visar att också kvinnliga hjältar eller hjältinnor i dag spelar en allt viktigare roll som dylika populärkulturella identifikationsobjekt. Att frågan om hjältar och statusövergångar inte enbart behandlas som en utvecklingsoptimistisk lovsång till vuxenhet via genomgångna "prov" av olika slag visas dock av filmer som kan betecknas som betydligt mer ambivalenta hjältesagor eller kanske snarare anti-hjältesagor. David Cronenbergs två senaste filmer $A$ History of Violence och Eastern Promises, båda med Viggo Mortensen, känd som kung Aragorn i Sagan om ringen-filmerna, som antihjälte, kan ses som exempel på vårt kluvna förhållande till hjältar och hjältemodiga handlingar i dag. Därmed blir de också påminnelser om att en vuxenhet som förväntas producera extraordinära effekter måste betraktas som en fantasi som innehåller farliga element ifall den förväxlas med den politiska och sociala verkligheten av i dag.

Speciellt intressant ur ett ålderskategoriperspektiv är kanske Guillermo del Toros Pans labyrinth där en liten flicka, Ofelia, har att genomgå en serie existentiella "test" för att visa sin hjältinnekapacitet. Ofelia måste alltså utföra vad man brukar kalla vuxna handlingar trots att hon är ett barn. Hon blir även utsatt för denna typ av vuxna handlingar i filmen som är en enastående stark, mardrömslik saga om behovet av att se verkligheten sådan den är, men även kunde vara, att ta ansvar och leva ett liv som känns meningsfullt (även om det kan leda till resultat som samtidigt kan uppfattas som tragiska).

\section{DEN OSYNLIGA VUXENFORSKNINGEN}

Varför har vuxenforskningen fått så liten synlighet inom det fält som här kallats ålderskategoriforskning? Ett svar som direkt inställer sig och som egentligen är implicit i det jag redan varit inne på är att kulturforskning av typen Cultural Studies så starkt har slagit igenom internationellt och numera även ganska starkt nationellt (både på finskt och rikssvenskt håll, i mindre utsträckning kanske inom finlandssvensk kulturforskning). Inom Cultural Studies har sammankopplingen vardagskultur, sam- 


\section{Sven-ERIK KLINKMANN}

tidskultur, ungdomskultur, subkultur och rock- och popkultur ofta varit betydande. Genomslaget för den här typen av forskning har antagligen gjort att andra grepp, som till exempel att studera fenomen ur en mer utpräglat kroppslig aspekt, inklusive frågor om förslitning, åldrande, död, kommit något i skymundan. Speciellt intressant är att vissa teoretiska traditioner - framför allt kanske då diskursanalys av olika typer - kopplats samman med den här formen av kulturforskning och gjort den till ett om inte allenarådande paradigm inom kulturforskningen så till ett mycket dominerande sådant. Man kan som ett mått på den snedvridning som skett vad gäller just ålderskategoriaspekten i samband med etableringen av Cultural Studies och teorier sammankopplade med den, studera ett verk som vill ge en översikt över det aktuella fältet kulturteori år 1995 när Cultural Studies kanske stod på toppen av sitt inflytande, i varje fall i den engelskspråkiga världen. Det gäller Johan Fornäs föredömligt välartikulerade och högst läsvärda Cultural Theory \& Late Modernity. Dess sätt att förhålla sig till ålderskategoriforskning är intressant. Att Fornäs som ungdomsforskare och rockforskare förväntas presentera en översikt med en viss övervikt för just de delarna av forskningsområdet ter sig ganska självklart. Ändå är det anmärkningsvärt att medan ungdomskultur i bokens index kan visa upp en lång lista med ytterligare stickord att gå vidare med saknas över huvud taget vuxenhet eller vuxen kultur som uppslagsord $\mathrm{i}$ indexet. Inte heller det mer neutrala ålder (age) kommer upp $\mathrm{i}$ indexet. Liknande obalanser kan man förvisso hitta på många andra håll.

Att ungdom kommit att förknippas med egenskaper som marginalitet, transgressivitet, revolt och kulturell omvandlingspotential tror jag är en av förklaringarna till att kulturforskningen inom ramen för det moderna och postmoderna så starkt ägnat just den ålderskategorin uppmärksamhet. I och med att forskarna själva åldras är det dock, banalt nog, antagligen också så att intresset för också andra ålderskategorier kommer att öka. För ungefär tio år sedan var jag själv med i en samnordisk forskargrupp som uttryckligen ägnade sig åt barn- och ungdomskultur. Gruppen kallade sig NUFF (Nordisk Ung Folk Forskning) och gav ut en antologi med titeln Younger than Yesterday, Older than Tomorrow (2002), där första delen av titeln är tagen från titeln till ett skivalbum med rockgruppen The Byrds från år 1967. Den titeln i sin tur är en parafras på en av sångerna på Byrds-albumet, Bob Dylans "My Back Pages", med refrängraderna "Ah, but I was so much older then, I'm younger than that now." Det anmärkningsvärda med NUFF-antologin och det forskningsmässiga grepp som tillämpas där är att ålderskategorin vuxenhet hela tiden finns med i den arsenal av olika ålderskategorier som de här barn- och ungdomsforskarna arbetar med. Som det sägs $i$ inledningen till boken utgör de olika ålderskategorierna, inkluderande ålderdom och vuxenhet, historiska och socialt baserade konstruktioner. Antologiredaktörerna konstaterar med anledning av en av texterna, skriven av folkloristen och barnforskaren Bjørg Kjær, att den neutralitet som vuxenhetspositionen tycks innebära är relaterad till det faktum att vuxenlivet i sig självt innehåller så utpräglat definierande krafter att vuxenheten blir osynliggjord som en specifik fas i livet. I stället kommer den att fungera som en referenspunkt för det som är naturligt och normalt, inte enbart i relation till vuxna utan också i relation till de livsfaser som barndom, ungdom och 


\section{I ÅLDERSKATEGORIERNAS GREPP}

ålderdom utgör. I Bjørg Kjærs text i boken samt hennes doktorsavhandling utvecklas resonemanget mer specifikt.

\section{EXCENTRICITET SOM EN FORM AV VUXENHET}

Kanske är det i sina utkanter som vuxenheten i dag blir på ett nytt sätt spännande och intressant också ur ett kulturanalytiskt forskningsperspektiv. En samhällsdebattör och "omstörtare" som Jean-Paul Sartre byggde, skriver film- och kulturforskaren Peter Wollen (2002), upp viktiga delar av sin verksamhet utgående ifrån fantasin om att han besatt en imaginär kropp som han så att säga genom en fantastisk operation lånat av sin ungdomsidol Pardaillan, den alltid rättrådige och modige franske svärdfäktande hjälten i Michel Zevacos romaner. Sartre skriver på sista sidan i sin självbiografi Orden att Pardaillan alltjämt bor inom honom.

Hur förhåller det sig då med en karaktär som tycks bli allt populärare i dagens kulturdebatt, inklusive mode, pop och kulturteori, nämligen excentrikern (Roth 2007; Salmi 2007)? I kulturhistorikern Kari Kallioniemis engelska kulturhistoria Blitzistä blairismiin. Englantilainen populaarikulttuuri ja ybteiskunta toisen maailmansodan jälkeen (2006) stiger excentrikern, exemplifierad av rockartisten Peter Gabriel, fram som en starkt ambivalent, därmed självfallet fascinerande konfiguration. Redan i själva begreppsligheten hos ordet excentriker ingår ett mått av anakronism och ålderdomlighet. Därom vittnar också rubriken på Kallioniemis kapitel om rockartisten Peter Gabriels excentricitet: "Moderni viktoriaani vai viimeinen rock-eksentrikko? Brittiläinen rocktähteys ja Peter Gabriel" ("En modern viktorian eller den siste rockexcentrikern? Brittisk rockstjärneskap och Peter Gabriel”). I Peter Gabriels musik och scenframträdanden ingår förutom rikligt med viktorianska referenser även inslag av äldre, förkristna traditioner, konstaterar Kallioniemi. Excentrikern framstår, så som Kallioniemi tecknar bilden av Peter Gabriel, som både omogen och vuxen på samma gång, som ett slags vuxet barn eller omogen vuxen.

Från excentrikern är steget inte långt till den åldrande gangstern eller cowboyen. Inte minst filmregissören Sam Peckinpahs westernfilmer erbjuder ett rikligt material vad gäller åldrande karaktärer, i filmer som Ride The High Country, The Wild Bunch, The Ballad of Cable Hogue och Junior Bonner. Åldrande, skröplighet, men också elegans, förfining sammanbinds ofta i Peckinpahs filmer med den elegiska, starkt nostalgiska tonen i filmerna där den gamla västern- och indiankulturens dagar förefaller för länge sedan passerade. När både människor och kulturer blir vuxna och gamla är steget till elegin, sorgesången inte långt. Ett exempel på en åldrande filmgangster med liknande eleganta, men även "omogna drag" utgör Burt Lancasters mobsterfigur Lou Pasco i Louis Malles Atlantic City. Lancaster-karaktären framstår som på något sätt oerhört omogen, ett slags barn mer än en avdankad playboy (vilket han också tycks ha varit), lite gripande och beklagansvärd på något sätt. Det är först när han i självförsvar och som ridderlig försvarare av Susan Sarandons heder, och även liv, i filmen skjuter ner två skurkar som han kan känna att han blivit vuxen "på riktigt". 


\section{SVEN-ERIK KLINKMANN}

Filosofen Norberto Bobbio som levde ett mycket långt liv skrev på sin ålders höst en essäsamling om hög ålder. Som Bobbio konstaterar är också hög ålder någonting som ofta uppfattas på ett ambivalent sätt. Gentemot den traditionella retorikens självförnöjde gamle, vise man står den gamla personen som saknar allt hopp. Mellan de två extremerna finns sedan en myriad av variationer vad gäller sättet att uppleva hög ålder: passivt accepterande, resignation, likgiltighet, masker som avser att förhindra en själv och andra från att se och acceptera rynkor och svagheter, revolt, världsfrånvändhet m.m. Forskningsmässigt har området undersökts av bland andra sociologen Mike Hepworth i en intressant liten volym med titeln Stories of ageing (2000). Hepsworths utgångmaterial utgörs av berättande om åldrande i populär litteratur (Charles Dickens, Oscar Wilde, Agatha Christie, Doris Lessing och många fler).

Sammanfattningsvis kan jag konstatera att resonemangen här ovan leder fram till en slutsats om vuxenhetens starkt kluvna natur. $\AA$ ena sidan betraktas vuxenheten som det "naturliga", auktoritativa, ofta även auktoritära, semiotiskt sett omärkta tillståndet $\mathrm{i}$ livsfasernas cykel. $\AA$ andra sidan blir den på ett märkligt sätt sammanpressad av de omgivande fasernas (barndom, ungdom, ålderdom) tydligen större symbolmässiga och metaforiska potential. Än en gång tycks Barbara Babcocks insikt stämma in också på dessa livscykler. Det är de socialt perifera faserna som visar sig symboliskt centrala, medan den socialt eller cykliskt sett centrala fasen kommer att framstå som symboliskt sett ointressant.

\section{KÄLLOR OCH LITTERATUR}

\section{Opublicerat material:}

BJÖRKQVIST, JESSIKA 2008: Symboler i Disneys Lejonkungen. Opublicerad uppsats, citerad med skribentens samtycke.

\section{Internetsidor:}

SALMI, HANNU 2007: Eksentrismiä: Jevgeni Bauerista Klaus Nomiin. 3. marraskuuta 2007. - Hannu Salmi: blogi [online]. http:// hannusalmi.blogspot.com/2007/11/ eksentrismi-ja-kummallisia-videoita.html> [3.11.2007.]

\section{Litteratur:}

ARNSTBERG, KARL-OLOV 2002: Ungdomens makt förtrollar och förgör. - Axess $2 / 2002$.

HEGGLI, GRY \& MARIT ANNE HAUAN (eds.) 2002: Younger than Yesterday, Older Than Tomorrrow. Cultural Perspectives on Contemporary Childhood and Youth. Turku: NNF. 


\section{I ÅLDERSKATEGORIERNAS GREPP}

HEPWORTH, MIKE 2000: Stories of Ageing. Buckingham \& Philadephia: Open University Press.

HORGBY, BJÖRN 2007: Rock och uppror. Amerikansk, brittisk och svensk rockkultur 1955-1969. Stockholm: Carlssons.

KALLIONIEMI, KARI 2006: Blitristä blairismïn. Englantilainen populaarikulttuuri ja ybteiskunta toisen maailmansodan jälkeen. Turku: Turun yliopisto, kulttuurihistoria.

KLINKMANN, SVEN-ERIK 2002: Populära fantasier frän Diana till Bayou Country. Vasa: Scriptum.

- 2005: Cultural Kinesthesis in Mediascapes. A Comment. - Ethnologia Scandinavica 35.

- 2007: Den kvinnliga, eviga skönhetens bilder - ansiktskrämer mot åldrande. - Budkavlen 2007.

KOTARBA, JOSEPH A. 2002: Rock 'n' Roll Music as a Timepiece. - Symbolic Interaction 25(3).

LINDBERG, ULF 1995: Rockens text. Ord, musik och mening. Stockholm: Symposion. MARTIN, BERNICE 1981: A Sociology of Contemporary Cultural Change. Oxford: Blackwell.

REYNOLDS, SIMON \& JOY PRESS 1995: The Sex Revolts. Gender, Rebellion, and Rock 'n' Roll. Cambridge, Massachusetts: Harvard UP.

ROTH, THOMAS 2007: Excentrikernas år. - Svenska Dagbladet, 30 december 2007.

SARTRE, JEAN-PAUL 1964: Orden. Stockholm: Bonniers/Söderströms. SJÖ, SOFIA 2007: Spelar kön någon roll när man räddar världen? Kvinnor, kvinnligheter och messiasmyter i SF-film. Åbo: Åbo Akademis förlag.

TSEËLON, EFRAT 1998: Kvinnan och maskerna. Lund: Studentlitteratur.

WOLLEN, PETER 2002: Paris Hollywood: Writings on Film. London: Verso.

Sven-Erik Klinkmann är docent i folkloristik vid Åbo Akademi, och särskilt intresserad av populärkultur. 